\title{
Learning horizon and optimal alliance formation
}

\author{
Hans T. W. Frankort ${ }^{1} \cdot$ John Hagedoorn ${ }^{2,3}$ • \\ Wilko Letterie ${ }^{4}$
}

(C) The Author(s) 2015. This article is published with open access at Springerlink.com

\begin{abstract}
We develop a theoretical Bayesian learning model to examine how a firm's learning horizon, defined as the maximum distance in a network of alliances across which the firm learns from other firms, conditions its optimal number of direct alliance partners under technological uncertainty. We compare theoretical optima for a 'close' learning horizon, where a firm learns only from direct alliance partners, and a 'distant' learning horizon, where a firm learns both from direct and indirect alliance partners. Our theory implies that in high tech industries, a distant learning horizon allows a firm to substitute indirect for direct partners, while in low tech industries indirect partners complement direct partners. Moreover, in high tech industries, optimal alliance formation is less sensitive to changes in structural model parameters when a firm's learning horizon is distant rather than close. Our contribution lies in offering a formal theory of the role of indirect partners in optimal alliance portfolio design that generates normative propositions amenable to future empirical refutation.
\end{abstract}

Hans T. W. Frankort

hans.frankort.1@city.ac.uk

John Hagedoorn

john.hagedoorn@rhul.ac.uk

Wilko Letterie

w.letterie@maastrichtuniversity.nl

1 Cass Business School, City University London, 106 Bunhill Row, London EC1Y 8TZ, UK

2 School of Management, Royal Holloway University of London, Egham, Surrey TW20 0EX, UK

3 UNU-MERIT, Maastricht University, Maastricht, The Netherlands

4 School of Business and Economics, Maastricht University, P.O. Box 616, 6200 MD Maastricht, The Netherlands 
Keywords Technological uncertainty - Alliance formation - Bayesian learning · Learning horizon · Indirect partners

JEL Classification $\quad \mathrm{D} 85 \cdot \mathrm{L} 14 \cdot \mathrm{O} 32$

\section{Introduction}

Scholars have long noted that technological uncertainty, defined as the difficulty of accurately predicting the future state of the technological environment, motivates firms to enter into alliances with other firms (Auster 1992; Eisenhardt and Schoonhoven 1996; Hagedoorn 2002; Mody 1993; Rosenkopf and Schilling 2007; Steensma et al. 2000). Alliances are an important mechanism for reducing technological uncertainty because they allow firms to learn from their alliance partners about relevant developments in the technological environment (Frankort et al. 2012; Frankort 2013; Gomes-Casseres et al. 2006; Mowery et al. 1996; Oxley and Wada 2009; Powell et al. 1996). However, alliances are not equally effective as an uncertainty-reduction mechanism in all circumstances, while they also induce costs. Therefore, the optimal number of alliances represents a balance between the uncertainty-reduction benefits and costs of alliances, so that a firm has enough alliances to reduce uncertainty effectively, but not so many as for costs to outweigh their benefits (Faems et al. 2012). Convergent with the existence of such a balance, empirical evidence shows that learning-related outcomes tend to be greatest at intermediate alliance portfolio size (Deeds and Hill 1996; Frankort et al. 2012; Lahiri and Narayanan 2013; Rothaermel and Deeds 2006; Vanhaverbeke et al. 2012, 2014).

Nevertheless, even though empirical evidence on optimal alliance portfolio size resonates with a basic trade-off between the uncertainty-reduction benefits and costs of alliances, the underlying theory has overwhelmingly centered on firms' direct partners as sources of learning and uncertainty reduction. This somewhat narrow focus on direct partners appears at odds with findings suggesting that alliances may also serve as conduits through which firms learn from their indirect partners, i.e., the set of firms that direct partners have access to through their own alliances (Ahuja 2000; Salman and Saives 2005; Soh and Roberts 2005; Vanhaverbeke et al. 2012). To the extent firms have the potential to learn not just from direct but also indirect partners, a fundamental question arises as to how learning from indirect partners affects the trade-off between the uncertainty-reduction benefits and costs of alliances. Answering this question is important because it is doubtful that the learning potential afforded by indirect partners is straightforwardly proportional to that afforded by direct partners. For example, firms vary greatly in their number of indirect partners for a given number of direct partners (e.g., Iyer et al. 2006), ${ }^{1}$ while

\footnotetext{
${ }^{1}$ For example, in the pharmaceutical biotechnology industry during 1990-1994, The Upjohn Company and Sepracor Inc. both had two direct partners, though these connected Upjohn to only two indirect partners while connecting Sepracor to well over twenty (Roijakkers and Hagedoorn 2006, p. 439). As another example, in the global semiconductor manufacturing industry during 1990-1996, both Matsushita Electric Industrial Co. Ltd. and Motorola Inc. had one direct partner, but Matsushita had two indirect
} 
they may also differ in the extent to which they are aware of (e.g., Lhuillery and Pfister 2011) and benefit from (e.g., Boyd and Spekman 2008; Ghosh and Rosenkopf 2014) such indirect partners. Motivated by these observations, and following a call to begin to consider the role of indirect partners in optimal alliance portfolio design (Lavie 2006, p. 651), we complement the study of optimal alliance formation under technological uncertainty with a systematic theory of how learning from indirect partners shapes a firm's optimal alliance portfolio size. Our specific research question is this: In the face of technological uncertainty, how does learning from indirect partners influence a firm's optimal number of direct partners?

We take a formal approach to answering this question. In particular, we derive normative propositions regarding optimal alliance formation from a theoretical Bayesian learning model of how firms facing technological uncertainty form alliances and then use those alliances to learn and thereby reduce such uncertainty. In addition to being considered a leading formal device for modeling decision making under uncertainty (Cyert and DeGroot 1987), a Bayesian learning framework is particularly well suited to address our specific research question. First, the Bayesian approach accords central importance to the initial uncertainty surrounding key parameters, while Bayesian updating subsequently allows actors to reduce such uncertainty through a mechanism of learning. This particular temporal sequence, in which actors respond to uncertainty by looking for learning opportunities that in turn help improve their beliefs about the uncertain parameter of interest, sits at the heart of the empirical phenomenon we are interested in modeling.

Second, a Bayesian learning framework allows us to model the effects of multiple parameters relevant to our research question in a tractable way. This is important because factors such as perceived technological uncertainty, the cost of unresolved uncertainty, the viability of interfirm learning, the cost of alliances, and awareness of indirect partners can vary greatly across firms and industries (e.g., Hagedoorn 2002; Harrigan 1985; Rosenkopf and Schilling 2007; Sutcliffe and Huber 1998), while all may individually as well as jointly shape the consequences of learning from indirect partners in perhaps unanticipated ways. A formal Bayesian learning framework, by requiring clear mathematical definitions of all relevant parameters and due to the rigor imposed by the Bayesian updating mechanism, allows us to generate an integrative and logically consistent account of any such effects (Adner et al. 2009).

In our Bayesian learning model, a firm begins with subjective beliefs about key features and trends characterizing an uncertain technological environment. The firm can update its beliefs by forming one or more alliances with other firms. The learning potential of the resulting set of alliances, and so the extent to which a firm can reduce technological uncertainty, is modeled as a function of the firm's learning horizon. We define a firm's learning horizon as the maximum distance in a firm's network of alliances across which that firm learns from other firms. We develop two canonical scenarios. In the first scenario, the firm learns only from its direct partners

Footnote 1 continued

partners while Motorola had six (Kapoor and McGrath 2014, p. 564). These examples foreshadow that the learning potential afforded by firms' respective sets of direct and indirect partners may vary independently. It follows that the theory of optimal alliance formation must explicitly account for heterogeneity in the extent to which distinct sets of indirect partners allow for learning and uncertainty reduction. 
and so we label its learning horizon as 'close'. In the second, the firm learns both from its direct and indirect partners and so we label its learning horizon as 'distant' instead. In our model, more precisely, a firm has a distant learning horizon if it is both aware of one or more indirect partners and able to learn from such partners. A comparison of the optimal alliance formation decisions in these distinct scenarios subsequently supplies precise normative propositions on how learning from indirect partners influences optimal alliance formation under technological uncertainty.

Our formal assessment of the relationship between firms' learning horizon and optimal alliance formation under technological uncertainty offers several key results. First, we show that a firm's learning horizon has distinct implications for optimal alliance formation depending on its industry context (e.g., Ahuja 2000, pp. 450-451). Specifically, in industries where technological uncertainty is comparatively high, residual uncertainty is costly, and where alliances are a comparatively affordable and effective solution to technological uncertainty (which we label 'high tech industries'), firms with a distant learning horizon can substitute alliance ties to indirect partners for those with direct partners. In contrast, in industries where technological uncertainty is comparatively low, residual uncertainty is less costly, and where alliances are a comparatively costly and ineffective solution to technological uncertainty (which we label 'low tech industries'), alliance ties to direct and indirect partners act as complements.

Second, we show that given a distant learning horizon, the optimal number of direct partners of a firm in a high tech industry will be more robust to inter-temporal changes in the cost of residual technological uncertainty, the cost of alliances, and the perceived level of technological uncertainty. Through a Bayesian lens, therefore, the inter-temporal stability of a firm's alliance activities may be understood as the strategically optimal outcome of its efforts to reduce technological uncertainty. This novel insight complements prior alliance research, which has often discussed intertemporal stability in firms' alliance activities through embeddedness and inertia mechanisms (e.g., Gulati and Gargiulo 1999; Hagedoorn 2006; Kim et al. 2006).

The paper is organized as follows: Sect. 2 introduces the basic setting and payoff structure in our model. Sections 3 and 4 develop expressions for optimal alliance formation under close and distant learning horizons, respectively. Section 5 compares the respective optimal decisions in equilibrium and derives our basic propositions. Section 6 generalizes the model to account for heterogeneous alliance formation and incomplete awareness of indirect partners. Section 7 discusses the findings and their implications.

\section{The basic model}

\subsection{Setting}

We consider a setting in which a firm performs research and development (R\&D) activities within an industry-level technological paradigm. A technological paradigm directs the search efforts of firms towards an optimal future technology along a technological trajectory (Breschi et al. 2000; Dosi 1982). A technological 
trajectory represents "...the activity of technological process along the economic and technological trade-offs defined by a paradigm..." (Dosi 1988, p. 1128). However, even though a technological paradigm produces some notion of what paths of research to pursue and avoid, the superiority of one direction over another is likely unclear a priori (Nelson and Winter 1982) and so a firm's expectations regarding an 'optimal' technological trajectory are inevitably imprecise.

We represent the optimal technological trajectory by a parameter $T$. We assume that a technological paradigm has one optimal technological trajectory $T$. An optimal trajectory is not necessarily the one that is closest to the technological frontier or technologically superior (Anderson and Tushman 1990; Arthur 1989; Liebowitz and Margolis 1995). Rather, it is the one that among conceivable alternatives appears most promising "on the ground of some rather obvious and broad criteria such as feasibility, marketability and profitability" (Dosi 1982, p. 155). Our assumption of one optimal trajectory is consistent with a flurry of industry cases documenting the eventual emergence of one comparatively dominant technology across settings as diverse as cement, glass, and minicomputers (Anderson and Tushman 1990), automobiles, electronic calculators, picture tubes, television, transistors, and typewriters (Suarez and Utterback 1995), as well as video tapes (Cusumano et al. 1992). Moreover, note that our assumption of one optimal technological trajectory does not preclude the contemporaneous existence of additional trajectories with some merit; all it requires is that at any one moment in time, prevailing technological, economic, and institutional constraints point to one technological trajectory that is on aggregate projected to be more feasible, marketable, and profitable.

Because the optimal technological trajectory depends on trade-offs along several technological, economic, and institutional dimensions and given that such trade-offs reflect a complex interplay between different actors (Dosi 1982; Garud et al. 1997), we assume that $T$ is exogenous to the R\&D activities of any one individual firm. If a firm had full information, it would make R\&D investments consistent with the technological trajectory as given by $T$. In what follows, we refer to $T$ as the optimal technology. We assume that each firm has incomplete knowledge about $T$, yet even though $T$ is uncertain, a firm nevertheless has initial expectations about $T$ based on available information (e.g., that accumulated through prior experience). We represent such initial expectations about the value of $T$ by a prior probability distribution that is normal with mean $\mu$ and variance $\sigma_{T}^{2}$, such that $T \sim N\left(\mu, \sigma_{T}^{2}\right)$. This prior probability distribution expresses a firm's initial perceived technological uncertainty.

\subsection{Payoffs}

The technology ultimately implemented by a firm is represented by the decision parameter $d$. For a decision $d$, a firm's cost function is given by $C(T, d)=b^{\prime}|T-d|$, where $b^{\prime}$ represents the cost a firm incurs when implementing a technology $d$ that deviates from the optimal technology $T$ by one unit and so $b^{\prime}>0$. This definition of $b^{\prime}$ allows for the possibility that a given deviation from $T$ is not equally costly in all 
settings. For example, it is conceivable that in industries where technological progress is comparatively more important, $b^{\prime}$-i.e., the marginal cost of getting $d$ wrong given $T$-is higher than in industries where technological progress is less important. Because of imperfect substitutability of R\&D outcomes across different trajectories and due to strong path dependencies within them (Dosi 1982; Nelson and Winter 1982; Sahal 1981), in practical terms one might view $C(T, d)$ as capturing the opportunity cost of suboptimal R\&D investment as well as the capital, effort, and time associated with adjusting to, and catching up with progress in, the optimal technological trajectory. The cost function shows that a firm incurs higher costs when the distance between $d$ and $T$ increases and so absent technological uncertainty, a firm would select $d=T$. However, complete certainty is improbable and so a firm will at best be able to reduce rather than eliminate uncertainty so as to pinpoint $T$ with greater precision. Because knowledge about $T$ is dispersed across firms within the industry, it is useful for firms to search for information to decrease technological uncertainty.

In our model, a firm can gather information about the properties of $T$ by forming one or more alliances with other firms and we represent the number of alliances formed by a firm by $\eta$. We assume that each alliance yields one direct observationi.e., one set of information about the optimal technology $T$. A firm begins with an initial belief represented by the prior probability distribution concerning $T$. Using the observations obtained from its alliances, the firm updates its prior probability distribution and forms a posterior belief-i.e., a posterior probability distribution concerning $T$-that incorporates the observations obtained through its alliances. This transformation or 'updating' of the prior belief concerning $T$ into a posterior belief about that parameter is what makes our model Bayesian. In particular, the posterior distribution of the optimal technology $T$ is obtained by deriving the distribution of $T$ conditional on the prior belief of the firm and on the observations obtained from its alliances. Based on this posterior belief about $T$, a firm chooses $d=d^{o p t}$ that minimizes the expected value of $C(T, d)$. Thus, $d=d^{o p t}$ is determined through $\min _{d} E C(T, \eta)$, where $E$ represents the expectations operator with respect to $T$ and the $\eta$ below $E$ denotes that a firm chooses $d$ based on the posterior probability distribution of $T$ after obtaining observations through its $\eta$ alliances.

The observations a firm obtains through its alliances are jointly normally distributed with mean $T$ and a covariance structure as will be given in Sect. 3, and the posterior probability distribution of $T$ is normal with mean $\mu_{\eta}$ and variance $\sigma_{\eta}^{2}$. The expression $\underset{T, \eta}{E} \mid T-d \mathrm{l}$ is minimized when $d$ equals the median of the probability distribution of $T$. As $T$ follows a normal distribution, the median and mean are equal and so $\min _{d} \underset{T, \eta}{E}|T-d|=\underset{T, \eta}{E}\left|T-\mu_{\eta}\right|=\underset{T, \eta}{E}|Y|$, where $Y$ follows a normal distribution with mean zero and variance equal to $\sigma_{\eta}^{2}$. The expected value of the absolute value of $Y$ is equal to $\underset{T, \eta}{E}|Y|=\sqrt{\frac{2 \sigma_{\eta}^{2}}{\pi}}$ (DeGroot 1970, pp. 232-233) and so it follows that

$$
\min _{d} \underset{T, \eta}{E} C(T, d)=b^{\prime} \sqrt{\frac{2 \sigma_{\eta}^{2}}{\pi}}=b \cdot \sigma_{\eta},
$$


where $\sigma_{\eta}$ is the standard deviation of a firm's posterior belief about $T$, reflecting a firm's residual technological uncertainty after it obtains sets of information through its alliances, and the parameter $b$ collects all constant terms. Note that while $\sigma_{\eta}$ plays a role in Eq. (1), $\mu_{\eta}$ does not. Additionally, while a firm may reduce its technological uncertainty through its $\eta$ alliances with other firms, each individual alliance involves a cost $c$ that captures the capital, effort, and time necessary to form, operate, and terminate that alliance. For tractability, we begin by interpreting the cost $c$ as a parameter that is stable both across alliances as well as across firms. However, this stability assumption can be relaxed without loss of generality and we take advantage of this possibility in Sect. 6, when generalizing our equilibrium results.

Consequently, the optimal number of alliances minimizes the total cost $T C$ :

$$
T C=\min _{\eta}\left(b \cdot \sigma_{\eta}+c \cdot \eta\right) .
$$

Thus, a firm's total cost is an increasing function of the posterior standard deviation $\sigma_{\eta}$ and so a firm has an incentive to minimize residual technological uncertainty (Hagedoorn et al. 2011; Letterie et al. 2007). As we will show later, because an increase in the number of alliances decreases $\sigma_{\eta}$, the optimal number of alliances represents a resolution of the trade-off between the uncertainty-reduction benefits of alliances on the one hand, and their costs (i.e., $c \cdot \eta$ ) on the other hand.

\section{Optimal alliance formation for a close learning horizon}

Consider the case where a firm's learning horizon is close and so it only learns through alliances with its own partners, but not through the alliances of its partners. The observation a firm receives through one alliance, which we represent by $x_{i}$, is normally distributed with mean $T$ and variance $\sigma_{x}^{2}$. We assume that individual observations are independent, such that an observation $x_{i}$ captures the nonredundant part of the information set obtained through one alliance. Thus, we assume that each alliance will yield at least some unique information as compared both with the firm's own knowledge and that accessed through its other alliances. This assumption is conceivable because individual firms tend not to have fully identical knowledge bases. It is also consistent with findings in empirical research showing that firms consider knowledge complementarity when selecting their alliance partners (Arora and Gambardella 1990; Mowery et al. 1998; Rothaermel and Boeker 2008). Note that this independence assumption is plausible, as each of a firm's partners must only hold some knowledge that is not held by the firm's other partners. Therefore, the independence assumption fully accommodates the possibility that the beliefs a firm's partners hold about the optimal technology $T$ are partly redundant, for example in case such partners also have alliances with one another (Ahuja 2000). By implication, the observations $x_{1}, x_{2}, \ldots, x_{\eta}$ that a firm obtains through its $\eta$ alliances are jointly normally distributed with mean $T$ and a covariance structure as given by a diagonal matrix $\Sigma_{x}$.

Each observation $x_{i}$ provides a set of information about $T$ but this information set will be imprecise to a greater or lesser extent (i.e., $\sigma_{x}^{2}>0$ ). First, due to the 
"permanent existence of asymmetries among firms, in terms of their...technologies" (Dosi 1988, p. 1155), information is scattered across industry firms and so no individual firm has full information about $T$. Second, to the extent that knowledge is tacit and embedded in routines and interactions within firms, its transmission across firm boundaries may be challenging (Kogut and Zander 1992). Third, to appropriate the returns to their knowledge, firms have a strategic reason to protect part of their knowledge about $T$ from leakage to their alliance partners (Oxley and Wada 2009). While such strategizing may lead firms to be protective of their in-house knowledge, we assume that firms will not purposely mislead their alliance partners and so strategic motives may affect the variance of an observation but not the mean.

Consequently, after a firm has acquired observations $x_{1}, x_{2}, \ldots, x_{\eta}$ through its $\eta$ alliances, it will face a residual level of technological uncertainty as given by the posterior variance of $T$ :

$$
\sigma_{\eta}^{2}=\left(\frac{\eta}{\sigma_{x}^{2}}+\frac{1}{\sigma_{T}^{2}}\right)^{-1}
$$

Derivation of this posterior variance is given in the Appendix. Equation (3) clearly shows that the Bayesian learning mechanism generates a posterior variance of $T$ that is conditional on both the prior belief of the firm regarding $T$ as well as the observations it obtains from its alliances. Substituting Eq. (3) into (2) and solving for the optimal number of alliances $\eta^{*}$ yields

$$
\eta^{*}=a \cdot\left(\sigma_{x}^{2}\right)^{1 / 3}-\frac{\sigma_{x}^{2}}{\sigma_{T}^{2}},
$$

where $a=\left(\frac{b}{2 c}\right)^{2 / 3}$, to save some notation. The optimal number of alliances is a continuous variable here but in practice a firm will choose an integer value close to $\eta^{*}$ yielding the lowest cost as implied by Eq. (2). Also, note that in our model, because firms choose the optimal (in the Bayesian sense) number of alliances $\eta^{*}$, in equilibrium no firm will have an incentive to deviate from this optimum.

Equation (4) provides a number of results. The optimal number of alliances increases with the cost of uncertainty $b$, while it decreases with the cost of alliances $c$. Moreover, the optimal number of alliances increases with a firm's perceived level of technological uncertainty $\sigma_{T}^{2}$. Consequently, initial technological uncertainty represents an inducement for firms to enter into alliances that will in turn increase firms' information about $T$, thus reducing their residual technological uncertainty $\sigma_{\eta}^{2}$. Descriptive findings are consistent with this result. In dynamic industry settings with high technological uncertainty, such as information technology or pharmaceutical biotechnology, firms tend to engage in more alliances than in more stable industry settings, such as food and beverages (Hagedoorn 2002). Equation (4) thus formally captures the widely-established notion that technological uncertainty constitutes an important motivation for firms to enter into alliances with other firms (Auster 1992; Hagedoorn 2002; Mody 1993; Rosenkopf and Schilling 2007).

Finally, to see how the optimal number of alliances depends on the variance of an observation $\sigma_{x}^{2}$, we obtain the first order derivative of $\eta^{*}$ with respect to $\sigma_{x}^{2}$ as follows: 


$$
\frac{\partial \eta^{*}}{\partial \sigma_{x}^{2}}=\frac{a}{3}\left(\sigma_{x}^{2}\right)^{-2 / 3}-\frac{1}{\sigma_{T}^{2}}=\left(\frac{a}{3}-\frac{\left(\sigma_{x}^{2}\right)^{2 / 3}}{\sigma_{T}^{2}}\right)\left(\sigma_{x}^{2}\right)^{-2 / 3}
$$

This derivative varies with the cost $b$ of residual (i.e., posterior) technological uncertainty $\sigma_{\eta}$ relative to the cost of alliances $c$, and the level of uncertainty $\sigma_{T}^{2}$ relative to the variance of an observation $\sigma_{x}^{2}$. Therefore, interpretation of the role of $\sigma_{x}^{2}$ in shaping $\eta^{*}$ is conditional on two distinct industry scenarios that we define as follows ${ }^{2}$ :

A high tech industry is one in which (1) the cost $b$ of residual technological uncertainty $\sigma_{\eta}$ is high relative to the cost of alliances $c$, and (2) the initial technological uncertainty $\sigma_{T}^{2}$ is high relative to the variance of an observation $\sigma_{x}^{2}$.

A low tech industry is one in which (1) the cost $b$ of residual technological uncertainty $\sigma_{\eta}$ is low relative to the cost of alliances $c$, and (2) the initial technological uncertainty $\sigma_{T}^{2}$ is low relative to the variance of an observation $\sigma_{x}^{2}$.

In a high tech industry, the first order derivative in Eq. (5) is positive and so a firm will form more alliances when the variance of observations becomes greater. As the incentive to learn through alliances in this setting is strong (loosely, $b>c$ and $\sigma_{T}^{2}>\sigma_{x}^{2}$ ), greater variance of observations induces a firm to establish more alliances. For a low tech industry, the first order derivative in Eq. (5) is negative and so a firm will form fewer alliances when the variance of observations increases. In this setting, the incentive to learn through alliances is weak (loosely, $b<c$ and $\sigma_{T}^{2}<\sigma_{x}^{2}$ ) and so greater variance of observations reduces a firm's inducement to establish more alliances. Therefore, in high tech industries, where technological uncertainty is severe and expensive, and where alliances are a comparatively affordable and effective solution to such uncertainty, a firm will form more alliances when the variance of observations increases. Conversely, in low tech industries, where technological uncertainty is limited and less expensive, and where alliances are a comparatively expensive and ineffective solution to such uncertainty, a firm will form fewer alliances when the variance of observations increases.

\section{Optimal alliance formation for a distant learning horizon}

Now consider the case where a firm's learning horizon is distant and so it learns both through alliances with its own partners as well as through indirect partners, defined as the set of firms that direct partners have access to through their own

\footnotetext{
${ }^{2}$ Our labeling of these two scenarios as 'high tech industry' and 'low tech industry' reflects the close consistency between empirically observed high tech and low tech industries and our theoretical definitions of both. For example, compared to low tech industries, the R\&D intensities of high tech industries are much higher (Dyer et al. 2014), while the marginal impact of firms' technology stocks on their value added and market valuations is also higher in high tech industries, such as pharmaceutical biotechnology (e.g., Cuneo and Mairesse 1984; Hall et al. 2005). This suggests that the level of technological uncertainty as well as the cost of residual technological uncertainty is much higher in high tech compared to low tech industries, thus outweighing the costs and learning imperfections of alliances, as reflected in high tech firms' greater propensity to engage in alliances with other firms (Hagedoorn 2002).
} 
alliances. Let each alliance partner have $\omega$ alliance partners itself. Because the focal firm is included in $\omega$, we must subtract one from $\omega$ to obtain the number of indirect partners provided by a direct partner. Therefore, each of a firm's direct partners yields $\omega-1$ indirect partners and so $\eta$ direct alliances yield $\eta \cdot(\omega-1)$ indirect observations. We assume that individual observations obtained through indirect partners, represented here by $x_{j}$, are independent and so each indirect partner will yield at least some unique information compared to the firm's own knowledge base, the knowledge bases of its direct alliance partners, and the knowledge bases of its other indirect partners.

For the reasons as outlined in the previous Section, the set of information about the optimal technology $T$ captured through an observation $x_{j}$ will be imprecise. Because an increase in distance between firms makes the movement of knowledge more challenging (Burt 2010), we assume that a firm's indirect partners yield more variable observations about $T$ than its direct partners. Specifically, in our model a firm observes $y_{j}=x_{j}+v_{j}$, where the stochastic term $v_{j}$ is normally distributed with mean zero and variance $\sigma_{v}^{2}$, the latter which represents the additional transmission noise surrounding an indirect observation compared to an observation drawn from a direct partner. While an indirect observation also has a mean $T$, its variance is $\sigma_{x}^{2}+\sigma_{v}^{2}$ and so the uncertainty-reduction potential of one indirect observation is smaller than that of one direct observation because $\sigma_{x}^{2}+\sigma_{v}^{2}>\sigma_{x}^{2}$.

With a distant learning horizon, after acquiring $\eta$ direct and $\eta \cdot(\omega-1)$ indirect observations, a firm faces a residual level of technological uncertainty as given by the posterior variance of $T$ :

$$
\sigma_{\eta}^{2}=\left(\frac{\eta}{\sigma_{x}^{2}}+\frac{\eta \cdot(\omega-1)}{\sigma_{x}^{2}+\sigma_{v}^{2}}+\frac{1}{\sigma_{T}^{2}}\right)^{-1}=\left(\frac{\eta}{\sigma_{x}^{2}} \cdot \frac{\left(\sigma_{v}^{2}+\omega \sigma_{x}^{2}\right)}{\left(\sigma_{x}^{2}+\sigma_{v}^{2}\right)}+\frac{1}{\sigma_{T}^{2}}\right)^{-1} .
$$

Note that the expression in Eq. (6) bears analogy to Eq. (3), except that it additionally accounts for the uncertainty-reduction potential of $\eta \cdot(\omega-1)$ indirect partners. In Eq. (3), which gives the posterior variance of $T$ for a close learning horizon, each observation obtained from one direct partner has a variance equal to $\left(\frac{1}{\sigma_{x}^{2}}\right)^{-1}=\sigma_{x}^{2}$. In Eq. (6), which instead gives the posterior variance of $T$ for a distant learning horizon, each observation obtained from one direct partner has a variance that is in the aggregate equal to $f(\omega)=\left(\frac{1}{\sigma_{x}^{2}} \cdot \frac{\left(\sigma_{v}^{2}+\omega \sigma_{x}^{2}\right)}{\left(\sigma_{x}^{2}+\sigma_{v}^{2}\right)}\right)^{-1}=\sigma_{x}^{2} \cdot \frac{\sigma_{x}^{2}+\sigma_{v}^{2}}{\sigma_{v}^{2}+\omega \sigma_{x}^{2}}<\sigma_{x}^{2}$. Consequently, though indirect observations themselves have greater transmission noise than direct observations, the overall variance of the combined information sets obtained through one of a firm's direct partners is smaller for a distant compared to a close learning horizon. Substituting Eq. (6) into (2) and solving for the optimal number of alliances $\eta^{* *}$ yields

$$
\eta^{* *}=a \cdot\left(\sigma_{x}^{2} \frac{\left(\sigma_{x}^{2}+\sigma_{v}^{2}\right)}{\left(\sigma_{v}^{2}+\omega \sigma_{x}^{2}\right)}\right)^{1 / 3}-\frac{\sigma_{x}^{2}}{\sigma_{T}^{2}} \frac{\left(\sigma_{x}^{2}+\sigma_{v}^{2}\right)}{\left(\sigma_{v}^{2}+\omega \sigma_{x}^{2}\right)} .
$$


Here, too, observe the analogy to Eq. (4) for a close learning horizon. Assuming for the moment that all firms are identical in their alliance formation strategies, we can impose the symmetry condition $\omega=\eta$ to obtain a Nash equilibrium as follows:

$$
\eta^{* *}=a \cdot\left(\sigma_{x}^{2} \frac{\left(\sigma_{x}^{2}+\sigma_{v}^{2}\right)}{\left(\sigma_{v}^{2}+\eta^{* *} \sigma_{x}^{2}\right)}\right)^{1 / 3}-\frac{\sigma_{x}^{2}}{\sigma_{T}^{2}} \frac{\left(\sigma_{x}^{2}+\sigma_{v}^{2}\right)}{\left(\sigma_{v}^{2}+\eta^{* *} \sigma_{x}^{2}\right)} .
$$

In our theoretical model this is a likely outcome because to this point, we have assumed that the payoffs and costs of alliance formation are symmetric. After we compare equilibria for close and distant learning horizons, we relax this symmetry condition in Sect. 6 in order to generalize our equilibrium results. A solution for Eq. (8) is not tractable but the expression nevertheless has properties directly relevant to our decision problem. For instance, an increase in the transmission noise $\sigma_{v}^{2}$ generates:

$$
\begin{aligned}
\lim _{\sigma_{v}^{2} \rightarrow \infty} \eta^{* *} & =\lim _{\sigma_{v}^{2} \rightarrow \infty} a \cdot\left(\sigma_{x}^{2} \frac{\left(\sigma_{x}^{2}+\sigma_{v}^{2}\right)}{\left(\sigma_{v}^{2}+\eta^{* *} \sigma_{x}^{2}\right)}\right)^{1 / 3}-\frac{\sigma_{x}^{2}}{\sigma_{T}^{2}} \frac{\left(\sigma_{x}^{2}+\sigma_{v}^{2}\right)}{\left(\sigma_{v}^{2}+\eta^{* *} \sigma_{x}^{2}\right)}=a \cdot\left(\sigma_{x}^{2}\right)^{1 / 3}-\frac{\sigma_{x}^{2}}{\sigma_{T}^{2}} \\
& =\eta^{*}
\end{aligned}
$$

Thus, for a distant learning horizon, if the variability of observations drawn from indirect partners increases, then a firm's uncertainty reduction progressively becomes a function of localized learning from direct partners alone. In that case, $\eta^{* *}$ asymptotically converges to $\eta^{*}$. The transmission noise $\sigma_{v}^{2}$ captures the inverse of a firm's ability to learn from indirect partners and so the intuition of Eq. (9) is that despite the presence of indirect partners, a firm nevertheless has a close learning horizon if it is unable to learn from indirect partners.

Next, to see how the optimal number of alliances given a distant learning horizon varies with the main parameters of the model, we restrict our attention to a high tech industry because in a low tech industry, equilibrium outcomes for several partial derivatives are indefinite. First note that in a high tech industry $f\left(\eta^{* *}\right)=\sigma_{x}^{2} \cdot \frac{\left(\sigma_{x}^{2}+\sigma_{v}^{2}\right)}{\left(\sigma_{v}^{2}+\eta^{* *} \sigma_{x}^{2}\right)}<\sigma_{x}^{2} ; \quad \frac{\partial f\left(\eta^{* *}\right)}{\partial \eta^{* *}}<0 ; \quad 0<\frac{\partial f\left(\eta^{* *}\right)}{\partial \sigma_{x}^{2}}<1 ; \quad \frac{\partial f\left(\eta^{* *}\right)}{\partial \sigma_{v}^{2}}>0 ; \quad$ and $\left(\frac{a}{3} f\left(\eta^{* *}\right)^{-2 / 3}-\frac{1}{\sigma_{T}^{2}}\right)>0$. Furthermore,

$$
\frac{\partial \eta^{* *}}{\partial a}=\frac{\left(f\left(\eta^{* *}\right)\right)^{1 / 3}}{1-\frac{\partial f\left(\eta^{* *}\right)}{\partial \eta^{* *}}\left(\frac{a}{3} f\left(\eta^{* *}\right)^{-2 / 3}-\frac{1}{\sigma_{T}^{2}}\right)}>0 .
$$

Recall that $a=\left(\frac{b}{2 c}\right)^{2 / 3}$ and so the optimal number of alliances increases with the cost of residual technological uncertainty $b$, while it decreases with the cost of alliances $c$, as in the case of a close learning horizon (see Eq. (4)). Also, the first order derivative of $\eta^{* *}$ with respect to a firm's perceived level of technological uncertainty $\sigma_{T}^{2}$ is 


$$
\frac{\partial \eta^{* *}}{\partial \sigma_{T}^{2}}=\frac{f\left(\eta^{* *}\right) / \sigma_{T}^{4}}{1-\frac{\partial f\left(\eta^{* *}\right)}{\partial \eta^{* *}}\left(\frac{a}{3} f\left(\eta^{* *}\right)^{-2 / 3}-\frac{1}{\sigma_{T}^{2}}\right)}>0
$$

Therefore, a firm's optimal number of direct partners increases if the firm perceives greater technological uncertainty. Next,

$$
\frac{\partial \eta^{* *}}{\partial \sigma_{v}^{2}}=\frac{\frac{\partial f\left(\eta^{* *}\right)}{\partial \sigma_{v}^{2}}\left(\frac{a}{3} f\left(\eta^{* *}\right)^{-2 / 3}-\frac{1}{\sigma_{T}^{2}}\right)}{1-\frac{\partial f\left(\eta^{* *}\right)}{\partial \eta^{* *}}\left(\frac{a}{3} f\left(\eta^{* *}\right)^{-2 / 3}-\frac{1}{\sigma_{T}^{2}}\right)}>0
$$

and so if the additional transmission noise surrounding an observation from an indirect partner becomes greater, then the number of direct partners increases to compensate for such additional variance. Similarly, note that

$$
\frac{\partial \eta^{* *}}{\partial \sigma_{x}^{2}}=\frac{\frac{\partial f\left(\eta^{* *}\right)}{\partial \sigma_{x}^{2}}\left(\frac{a}{3} f\left(\eta^{* *}\right)^{-2 / 3}-\frac{1}{\sigma_{T}^{2}}\right)}{1-\frac{\partial f\left(\eta^{* *}\right)}{\partial \eta^{* *}}\left(\frac{a}{3} f\left(\eta^{* *}\right)^{-2 / 3}-\frac{1}{\sigma_{T}^{2}}\right)}>0
$$

and so the number of direct partners increases when the variability of observations obtained through a firm's direct partners increases.

\section{Comparing equilibria}

Having developed the Bayesian analysis for both close and distant learning horizons, we now turn to a comparison of $\eta^{*}$ and $\eta^{* *}$, the respective optimal decisions for the two scenarios. We begin with two key insights from the prior Sections. First, equilibrium outcomes respond differently to increases in information variability depending on the context because $\frac{\partial \eta^{*}}{\partial \sigma_{x}^{2}}>0$ in a high tech industry whereas $\frac{\partial \eta^{*}}{\partial \sigma_{x}^{2}}<0$ in a low tech industry. Second, for a distant learning horizon each observation through a direct partner has a variance that is, in the aggregate, equal to $f\left(\eta^{* *}\right)=\sigma_{x}^{2} \cdot \frac{\left(\sigma_{x}^{2}+\sigma_{v}^{2}\right)}{\left(\sigma_{v}^{2}+\eta^{* *} \sigma_{x}^{2}\right)}<\sigma_{x}^{2}$ and so the overall variability of information a firm obtains through its alliances is smaller for a distant rather than a close learning horizon.

A change from a close to a distant learning horizon can be viewed as an aggregate decrease in information variability. By Sects. 3 and 4, this has opposing implications in high versus low tech industries. Specifically, in a high tech industry $\frac{\partial \eta^{*}}{\partial \sigma_{x}^{2}}>0$ and so a firm will form fewer alliances if the variability of observations decreases. By this result, and because $f\left(\eta^{* *}\right)=\sigma_{x}^{2} \cdot \frac{\left(\sigma_{x}^{2}+\sigma_{v}^{2}\right)}{\left(\sigma_{v}^{2}+\eta^{* *} \sigma_{x}^{2}\right)}<\sigma_{x}^{2}$, a static comparison of $\eta^{*}$ and $\eta^{* *}$ (Eqs. (4) and (8)) generates a smaller optimum for a distant compared to a close learning horizon, i.e., $\eta^{*}>\eta^{* *}$. This generates the following proposition: 
Proposition 1 In a high tech industry, a firm's optimal number of alliances is smaller when it has a distant rather than a close learning horizon.

Thus, in a high tech industry, a firm with a distant learning horizon can substitute alliance ties to indirect partners for those with direct partners. Conversely, if the learning horizon is close-i.e., a firm has no indirect partners or it does have, but cannot learn from, such partners-then a firm's optimal number of alliances becomes greater.

In a low tech industry $\frac{\partial \eta^{*}}{\partial \sigma_{x}^{2}}<0$ and so a firm will form more alliances if the information variability of observations decreases. By this result, and because $f\left(\eta^{* *}\right)=\sigma_{x}^{2} \cdot \frac{\left(\sigma_{x}^{2}+\sigma_{v}^{2}\right)}{\left(\sigma_{v}^{2}+\eta^{*} \sigma_{x}^{2}\right)}<\sigma_{x}^{2}$, a static comparison of $\eta^{*}$ and $\eta^{* *}$ (Eqs. (4) and (8)) generates a larger optimum for a distant compared to a close learning horizon, i.e., $\eta^{*}<\eta^{* *}$. This generates the following proposition:

Proposition 2 In a low tech industry, a firm's optimal number of alliances is greater when it has a distant rather than a close learning horizon.

Thus, in a low tech industry, a distant learning horizon instead generates complementarity between a firm's alliance ties to direct and indirect partners: a firm that learns both from direct and indirect partners will benefit more from a larger number of direct partners.

One key insight following directly from our analysis is that though a firm's learning horizon does have an impact on optimal alliance formation, the nature of this association depends on characteristics of the industry context within which the firm is embedded (here, whether the industry is low tech or high tech). Together, Propositions 1 and 2 reinforce Ahuja's (2000, pp. 450-451) suggestion that the nature of the interaction between ties to direct and indirect partners " ... can only be understood relative to a particular context..."

Though Propositions 1 and 2 represent static implications of the Bayesian learning model, the analysis also has dynamic implications for firms in a high tech industry. Suppose a firm optimizes its number of alliances every period as a consequence of period-by-period changes in the structural parameters of the model. Then, its optimal decision and so its optimal number of alliances may vary by period. Indeed, the sensitivity of a firm's optimal number of alliances to changes in structural model parameters may differ between close and distant learning horizons.

To examine such a dynamic effect, we focus our attention on $b, c$, and $\sigma_{T}^{2}$ because dynamic implications of changes in the variance of an observation $\sigma_{x}^{2}$ are indefinite. We first obtain the partial derivatives of $\eta^{*}$ with respect to the structural parameters $a$ (capturing $b$ and $c$ ) and $\sigma_{T}^{2}$ and then use the properties of $f(\eta)$ to compare these partial derivatives to Eqs. (10) and (11), respectively. For a close learning horizon, the relevant partial derivatives of $\eta^{*}$ are $\frac{\partial \eta^{*}}{\partial a}=\left(\sigma_{x}^{2}\right)^{1 / 3}$ and $\frac{\partial \eta^{*}}{\partial \sigma_{T}^{2}}=\frac{\sigma_{x}^{2}}{\sigma_{T}^{4}}$. Next, recall that $f\left(\eta^{* *}\right)=\sigma_{x}^{2} \cdot \frac{\left(\sigma_{x}^{2}+\sigma_{v}^{2}\right)}{\left(\sigma_{v}^{2}+\eta^{*} \sigma_{x}^{2}\right)}<\sigma_{x}^{2}$, which means that the numerator of the expression $\frac{\left(f\left(\eta^{* *}\right)\right)^{k}}{1-\frac{\partial f\left(\eta^{* *}\right)}{\partial \eta^{* *}}\left(\frac{a}{3}\left(\eta^{* *}\right)^{-2 / 3}-\frac{1}{\sigma_{T}^{2}}\right)}$, which itself appears as the numerator in the respective partial 
derivates of $\eta^{* *(E q s . ~(10) ~ a n d ~(11)), ~ i s ~ s m a l l e r ~ t h a n ~}\left(\sigma_{x}^{2}\right)^{k}$, where $k \in\{1 / 3 ; 1\}$. The denominator, i.e., $1-\frac{\partial f\left(\eta^{* *}\right)}{\partial \eta^{* *}}\left(\frac{a}{3} f\left(\eta^{* *}\right)^{-2 / 3}-\frac{1}{\sigma_{T}^{2}}\right)$, is larger than 1 because $\frac{\partial f\left(\eta^{* *}\right)}{\partial \eta^{* *}}<0$, and $\left(\frac{a}{3} f\left(\eta^{* *}\right)^{-2 / 3}-\frac{1}{\sigma_{T}^{2}}\right)>0$ in a high tech industry. Therefore, a comparison of the relevant first order derivatives of $\eta^{*}$ and $\eta^{* *}$ with respect to $b, c$, and $\sigma_{T}^{2}$ generates the following proposition:

Proposition 3 In a high tech industry, the optimal number of alliances is less sensitive to changes in the structural parameters $b, c$, and $\sigma_{T}^{2}$ when a firm has a distant rather than a close learning horizon (i.e., $0<\frac{\partial \eta^{* *}}{\partial a}<\frac{\partial \eta^{*}}{\partial a}$ and $0<\frac{\partial \eta^{* *}}{\partial \sigma_{T}^{2}}<\frac{\partial \eta^{*}}{\partial \sigma_{T}^{2}}$ ).

The ordering of the first-order derivatives in Proposition 3 implies that a firm's optimal number of direct partners is expected to be more stable-i.e., less sensitive to changes in $b, c$, and $\sigma_{T}^{2}$-if the firm learns both from direct and indirect partners. To see why this happens, note that our Bayesian model and the resulting Nash equilibrium explicitly account for firms considering the alliance formation behavior of their direct partners. Indeed, even though parameters $b, c$, and $\sigma_{T}^{2}$ are assumed exogenous to individual firms, in the case of a distant learning horizon, a focal firm calibrates optimal alliance formation in part based on its expectations concerning partners' alliance formation. Because in that case, a firm can benefit from learning from indirect partners, it will determine optimal alliance formation keeping in mind such indirect learning benefits. These indirect benefits are absent in the case of a close learning horizon, which in turn gives rise to the contrast between close and distant learning horizons as summarized in Proposition 3.

For example, let us assume that perceived technological uncertainty $\sigma_{T}^{2}$ increases, which represents an exogenous shock that might be due to, for example, the discovery of an additional trajectory within a technological paradigm. By Eqs. (3) and (6), the effect of such a shock would be to increase the posterior variance of $T$ i.e., the residual technological uncertainty faced by the firm. Equations (4) and (8) indicate that such an increase in $\sigma_{T}^{2}$ is a motivation for the firm to increase its number of alliances, both for close and distant learning horizons. Crucially though, the partners of the firm will be similarly motivated and so in case of a distant learning horizon, the firm's increased learning requirement will be satisfied in part by its partners' alliance formation. In our model, the optimal number of alliances in the resulting equilibrium explicitly takes into account the alliance formation patterns of partners. Compared to a close learning horizon, this is the mechanism reducing variance in the focal firm's optimal number of alliances under a distant learning horizon. A similar line of reasoning holds for the effects of parameters $b$ and $c$. Compared to a close learning horizon, a firm's distant learning horizon in a high tech industry therefore acts as a buffer from changes in several structural model parameters because in equilibrium the firm accounts for partners' responses to such changes. 


\section{Generalizing the model}

\subsection{Heterogeneous alliance formation}

Thus far, we have assumed that $\omega=\eta$ in order to obtain a symmetric Nash equilibrium, while we also treated a focal firm as having access to $\omega-1$ indirect partners. First, even if $\omega=\eta$, the latter assumption is restrictive because some of partners' direct partners may be 'redundant' from the perspective of a focal firm, in that they might themselves be direct partners of the firm as well (Ahuja 2000; Walker et al. 1997). Moreover, multiple direct partners might have alliances with one and the same indirect partner. In both scenarios, a focal firm's number of nonredundant, unique indirect partners will be smaller than $\omega-1$. Second, the assumption that $\omega=\eta$ is itself restrictive because firms tend to differ in their number of alliance partners (e.g., Roijakkers and Hagedoorn 2006; Kapoor and McGrath 2014; Powell et al. 1996). Such heterogeneity may be, for example, due to differences in the costs firms incur to form, operate, and terminate an alliance. Indeed, though to this point we have interpreted the cost $c$ as a parameter that is stable both across alliances as well as across firms, this stability assumption can be relaxed without loss of generality. ${ }^{3}$ In this Section, we generalize our model to allow explicitly for heterogeneous alliance formation.

Let $\varpi-1$ be the average number of indirect partners that are 'non-redundant' from the perspective of a focal firm. Then, by Eq. (7) a firm's optimal number of alliances is given by

$$
\eta^{\dagger}=a \cdot f(\varpi)^{1 / 3}-\frac{f(\varpi)}{\sigma_{T}^{2}},
$$

where $f(\varpi)=\sigma_{x}^{2} \cdot \frac{\left(\sigma_{v}^{2}+\sigma_{x}^{2}\right)}{\left(\sigma_{v}^{2}+\varpi \sigma_{x}^{2}\right)}$. In this setting, Propositions 1 and 2 will hold if $f(\varpi)<\sigma_{x}^{2}$, which requires that the number of unique indirect partners is positive, i.e. $\varpi-1>0$. This condition will be satisfied if it is possible for the direct partners of a firm to give access to at least strictly more than an average of zero non-redundant, unique indirect partners. The opportunity for non-redundancy appears to be a weak requirement, first, given the hundreds and often thousands of firms populating many industries (e.g., United States Census Bureau 2012). Second, empirical research shows that non-redundancy is prevalent even in networks with high degrees of local redundancy, due to the propensity of some firms to form 'bridging' ties across otherwise disconnected parts of an alliance network (e.g., Powell et al. 2005; Rosenkopf and Padula 2008; Schilling and Phelps 2007; Sytch et al. 2011). In this more general model, then, not all direct partners of the firm are required to have unique partners themselves: even if only one of a firm's direct partners has one unique partner itself, a distant learning horizon can exist and so the necessary conditions for Propositions 1 and 2 are replicated. Therefore, by relaxing the

\footnotetext{
${ }^{3}$ Specifically, this more general assumption amounts to interpreting $c$ as the expected cost of forming, operating, and terminating an alliance.
} 
symmetry condition through allowing $\varpi \neq \eta$, we impose much weaker sufficiency conditions on Propositions 1 and 2.

This generalization of our model to account for heterogeneous alliance formation allows for a descriptive comparison between key implications of Propositions 1 and 2 and performance in empirically-observed alliance portfolios. One key implication of Proposition 1 is that in a high tech industry the number of direct alliance partners optimal for technological learning is smaller for firms with a more extensive learning horizon. This implication is fully consistent with results in Ahuja (2000) and Vanhaverbeke et al. (2012), suggesting that the number of direct alliance partners optimal for learning in a number of technology-intensive industries during 1981-1996 was smaller for firms with greater numbers of indirect partners. One key implication of Proposition 2 is that in a low tech industry the optimal number of direct alliance partners is instead greater for firms with a more extensive learning horizon. Consistent with this implication, Koka and Prescott (2008) show that in the low tech steel industry during 1980-1994, firms that simultaneously had greater numbers of direct as well as indirect partners outperformed others, and this effect was even more pronounced during periods of environmental stability.

We now turn to generalizing Proposition 3. Given that $\frac{\partial \eta^{*}}{\partial a}=\left(\sigma_{x}^{2}\right)^{1 / 3}$, it is straightforward to show that

$$
\begin{aligned}
\frac{\partial \eta^{\dagger}}{\partial a}= & f(\varpi)^{1 / 3}+\left(\frac{a}{3} f(\varpi)^{-2 / 3}-\frac{1}{\sigma_{T}^{2}}\right) \cdot \frac{\partial f(\varpi)}{\partial \varpi} \cdot \frac{\partial \varpi}{\partial a} \leq \frac{\partial \eta^{*}}{\partial a} \\
& +\left(\frac{a}{3} f(\varpi)^{-2 / 3}-\frac{1}{\sigma_{T}^{2}}\right) \cdot \frac{\partial f(\varpi)}{\partial \varpi} \cdot \frac{\partial \varpi}{\partial a} .
\end{aligned}
$$

Furthermore, $\frac{\partial f(\pi)}{\partial \varpi}=-\sigma_{x}^{4} \cdot \frac{\left(\sigma_{x}^{4}+\sigma_{x}^{2} \sigma_{v}^{2}\right)}{\left(\sigma_{v}^{2}+\varpi \sigma_{x}^{2}\right)^{2}}<0$ and in a high tech industry $\left(\frac{a}{3} f(\varpi)^{-2 / 3}-\frac{1}{\sigma_{T}^{2}}\right)>0$. Thus, it follows that $\frac{\partial \eta^{\dagger}}{\partial a} \leq \frac{\partial \eta^{*}}{\partial a}$ if $\frac{\partial \varpi}{\partial a}>0$ and so if both $\frac{\partial \eta}{\partial a}>0$ and $\frac{\partial \omega}{\partial a}>0$, then the main features of Proposition 3 are replicated. In practice, this requires that both a firm and its average partner increase their number of alliances in response to an increase in the parameter $a=\left(\frac{b}{2 c}\right)^{2 / 3}$, reflecting an increase in the cost of residual technological uncertainty $b$ relative to the cost of alliances $c$.

Similarly, because $\frac{\partial \eta^{*}}{\partial \sigma_{T}^{2}}=\frac{\sigma_{x}^{2}}{\sigma_{T}^{4}}$,

$$
\begin{aligned}
\frac{\partial \eta^{\dagger}}{\partial \sigma_{T}^{2}}= & \frac{f(\varpi)}{\sigma_{T}^{4}}+\left(\frac{a}{3} f(\varpi)^{-2 / 3}-\frac{1}{\sigma_{T}^{2}}\right) \cdot \frac{\partial f(\varpi)}{\partial \varpi} \cdot \frac{\partial \varpi}{\partial \sigma_{T}^{2}} \leq \frac{\partial \eta^{*}}{\partial \sigma_{T}^{2}} \\
& +\left(\frac{a}{3} f(\varpi)^{-2 / 3}-\frac{1}{\sigma_{T}^{2}}\right) \cdot \frac{\partial f(\varpi)}{\partial \varpi} \cdot \frac{\partial \varpi}{\partial \sigma_{T}^{2}} .
\end{aligned}
$$


As in the above, if both $\frac{\partial \eta}{\partial \sigma_{T}^{2}}>0$ and $\frac{\partial \omega}{\partial \sigma_{T}^{2}}>0$, the sensitivity of a firm's number of alliances in case of a distant learning horizon is lower than that for a close learning horizon, i.e., $\frac{\partial \eta}{\partial \sigma_{T}^{2}} \leq \frac{\partial \eta^{*}}{\partial \sigma_{T}^{2}}$.

Under these two fairly general assumptions, the key properties of Proposition 3 are replicated, generating the following proposition:

Proposition 4 In a high tech industry, if alliance formation is heterogeneous (i.e., $\varpi \neq \eta)$ and firms are homogeneous in the sign of their sensitivity (i.e., both $\frac{\partial \eta}{\partial a}>0$ and $\frac{\partial \omega}{\partial a}>0$, and both $\frac{\partial \eta}{\partial \sigma_{T}^{2}}>0$ and $\left.\frac{\partial \omega}{\partial \sigma_{T}^{2}}>0\right)$, then the optimal number of alliances is less sensitive to changes in the structural parameters $b, c$, and $\sigma_{T}^{2}$ when a firm has a distant rather than a close learning horizon (i.e., $0<\frac{\partial \eta^{\dagger}}{\partial a}<\frac{\partial \eta^{*}}{\partial a}$ and $\left.0<\frac{\partial \eta^{\dagger}}{\partial \sigma_{T}^{2}}<\frac{\partial \eta^{*}}{\partial \sigma_{T}^{2}}\right)$

Therefore, once we allow for heterogeneous alliance formation, which only introduces weak additional constraints, the influence of a firm's learning horizon on the sensitivity of the firm's optimal number of alliances to changes in structural model parameters is identical in Proposition 4 compared to Proposition 3. One key implication of Proposition 4 is that relative to a firm with a more restricted learning horizon, a firm with a more extensive learning horizon benefits more from a given level of inter-temporal stability in its number of direct alliance partners. As an illustrative example, consider Advanced Micro Devices Inc. (AMD) and National Semiconductor Corporation (NSC) during 1977-1999. ${ }^{4}$ Both firms operated mainly in the semiconductors subsector of the high tech information technology industry, a setting that has historically experienced great variation in the level of technological uncertainty, the cost of residual technological uncertainty, and the cost of alliances (e.g., Bresnahan and Greenstein 1999; Frankort 2013; Grove 1996; Kapoor 2013; Schilling 2015; Sytch et al. 2011), and so we might expect a priori that the learning horizon may have an effect consistent with Proposition 4.

AMD and NSC were similar on a number of dimensions. For example, both had their home in Silicon Valley and were among few semiconductors companies having remained independent by the end of the 1970s (Chandler 2005). Moreover, average annual R\&D investments were similar between the two firms, at around \$235MM, while both divided their alliance activities across IT subsectors in comparable ways, with around $80 \%$ of the alliances in microelectronics. They also had similar shares of contractual alliances compared to joint ventures. Finally, the extent to which partners had alliances among themselves-i.e., the density of the two alliance portfolios - was comparable as well. Despite all such similarities, however, AMD on average outperformed NSC by about $80 \%$ on patent-based

\footnotetext{
${ }^{4}$ We developed this brief comparative case example based on combined data drawn from the Cooperative Agreements and Technology Indicators database (alliance data, 1977-1999), the NBER patent data file (data on technological learning in IT, 1977-1999), as well as searches of historical annual reports in Mergent Online and Mergent Archives (additional data, 1978-1999). Details are available upon request.
} 
measures of technological learning, which raises the question: what might explain such a differential? Our theory related to Proposition 4 would predict that part of the difference in technological learning may have been due to the comparatively greater benefit AMD derived from the stability in its number of direct partners, afforded by a more extensive distant learning horizon. Indeed, though the alliance portfolios of both firms were equally stable in terms of inter-temporal variance in numbers of direct partners, the extent of the learning horizon of AMD, in terms of numbers of indirect partners per direct partner, was on average more than 1.2 times that of NSC.

\subsection{Incomplete awareness}

In his classic treatment of interorganizational relationship formation, Van de Ven (1976, p. 31, italics added) noted that "organizations must be aware of possible sources...where their needed resources can be obtained; otherwise organizational directors are likely to conclude that the goal or need which motivates the search for resources cannot be attained." To this point, we have treated firms' awareness of indirect partners strictly dichotomously: firms are either unaware (i.e., a close learning horizon) or fully aware of all their non-redundant, unique indirect partners (i.e., $\varpi>1$ ). However, there can be a discrepancy between a firm's total number of unique indirect partners (i.e., $\eta \cdot(\varpi-1))$ and those that the firm knows to exist. ${ }^{5}$ In this Section, we focus on a further generalization of our model to account for incomplete awareness.

To incorporate incomplete awareness into our theory, it suffices to let $\varpi^{\prime}-1$ be the average number of non-redundant indirect partners that a focal firm is aware of. It is straightforward to see that the necessary conditions for Propositions 1 and 2 are replicated if $\varpi^{\prime}>1$. Hence, regardless of a firm's actual number of unique indirect partners, as soon as it is aware of at least one such partner (i.e., $\varpi^{\prime}>1$ ), Propositions 1 and 2 will hold. Turning to Proposition 4, if $\varpi^{\prime}$ rather than $\varpi$ is the relevant parameter from the standpoint of a firm facing an alliance formation decision, the features of Proposition 4 are replicated if a firm with a greater number of unique indirect partners is aware of more such partners than a firm with a smaller number of unique indirect partners, i.e., $\operatorname{corr}\left(\varpi, \varpi^{\prime}\right)>0$. This assumption is reasonable because the alliance portfolio of a firm with a greater number of partners should be more visible than that of a firm with a smaller number of partners.

Because $\sigma_{v}^{2}$ represents the inverse of a firm's ability to learn from indirect partners, we can now be more precise in our distinction between close and distant learning horizons. If a firm is unaware of unique indirect partners (i.e., $\varpi^{\prime}=1$ ), then its ability to learn from them is irrelevant and so the firm has a close learning horizon. Instead, if the firm is aware of at least one unique indirect partner (i.e., $\varpi$ ' $>1$ ) and it is able to learn from that partner (i.e., $\sigma_{v}^{2}<\infty$ ), then it has a distant learning horizon. Therefore, neither awareness nor ability alone is sufficient for a

\footnotetext{
5 This possibility is fully consistent with the literature on competitor identification, suggesting that cognitive limitations may lead to discrepancies between firms' industry environments and cognitive models of such environments (Porac et al. 1995), which can have consequences for firm decision making (Zajac and Bazerman 1991). To date, the implications of such cognitive constraints have remained largely unaddressed in the alliance literature (Westphal 2008).
} 
firm to act on the learning potential afforded by non-redundant indirect partners. In particular, all effects summarized in Propositions 1, 2, and 4 will hold if both $\varpi^{\prime}>1$ and $\sigma_{v}^{2}<\infty$.

Though our labeling of learning horizons as close or distant at first blush suggests that the learning horizon concept has a strictly binary interpretation, the extent of the learning potential associated with different learning horizons actually represents a continuum, with three boundary scenarios. First, firms without indirect partners, those that have indirect partners yet without awareness of them, or those that have indirect partners yet without the ability to learn from them have the most restricted learning horizon, which we labeled a close learning horizon. Second, firms that are aware of one unique indirect partner and are at least minimally able to learn from that partner have the most restrictive distant learning horizon. Third, firms with many indirect partners that they are both aware of and able to learn from have the most extensive distant learning horizon.

\section{Discussion}

To begin to consider the role of indirect partners in optimal alliance portfolio design (e.g., Lavie 2006, p. 651), we asked how learning from indirect partners influences a firm's optimal number of direct partners in the face of technological uncertainty. Our formal Bayesian learning model of optimal alliance formation demonstrated, first, that a firm's learning horizon has distinct normative implications for optimal alliance formation depending on the firm's specific industry context. In a high tech industry, where technological uncertainty is comparatively high, residual uncertainty is costly, and where alliances are a comparatively affordable and effective solution to technological uncertainty, firms with a distant learning horizon can substitute alliance ties to indirect partners for those with direct partners. In contrast, in a low tech industry, where technological uncertainty is comparatively low, residual uncertainty is less costly, and where alliances are a comparatively costly and ineffective solution to technological uncertainty, alliance ties to direct and indirect partners act as complements. These basic implications of our model resonate with recent literature analyzing complementarities across firms' learning activities (e.g., Cassiman and Veugelers 2006), by suggesting that the question of whether alliance ties to direct and indirect partners are complements or substitutes must be answered with reference to relevant contextual variables (Ahuja 2000, pp. 450-451).

Second, our model implies that in a high tech environment and relative to a firm with a more restricted learning horizon, a firm with a more extensive learning horizon benefits more from a given level of inter-temporal stability in its number of direct alliance partners. In particular, given a distant learning horizon, the optimal number of direct partners of a firm in a high tech industry will be more robust to inter-temporal changes in the cost of residual technological uncertainty, the cost of alliances, and the perceived level of technological uncertainty. Therefore, in high tech industries, the inter-temporal stability of some firms' alliance activities may be 
understood as the strategically optimal outcome (in the Bayesian sense) of firms' efforts to reduce technological uncertainty. Our novel strategic explanation for inter-temporal stability in firms' alliance activities complements prior research that has often discussed such stability in terms of embeddedness and inertia mechanisms (e.g., Gulati and Gargiulo 1999; Hagedoorn 2006; Kim et al. 2006).

Our treatment of the learning horizon concept captures in an integrative way various factors of importance when considering the role of indirect partners in optimal alliance portfolio design. At a basic level, it allows firms to vary in their number of indirect partners for a given number of direct partners. Though existing research has already begun to account for such a possibility (Ahuja 2000; Vanhaverbeke et al. 2012), it has nevertheless implicitly assumed that firms' learning from indirect partners is purely a function of the number of such partners. More broadly, it has tended to assume that knowledge flows fairly easily beyond individual alliance dyads, for example, between indirectly connected firms (Ghosh and Rosenkopf 2014). However, a firm with five indirect partners may be aware of all five yet have a limited ability to learn from them, while an otherwise identical firm may be aware of only two indirect partners yet have a strong ability to learn from these two. To account for such heterogeneity, our model formally incorporates as relevant parameters the extent to which firms are aware of and able to learn from their indirect partners. This way, our theory facilitates a refocusing, away from the assumption that firms' learning from indirect partners is a direct function of the actual number of such partners, towards a more nuanced account that considers both firms' cognitive limitations in observing other firms (Westphal 2008) as well as limitations in learning from them (Burt 2010; Ghosh and Rosenkopf 2014).

Further opportunities exist to extend our research as well as address some of its limitations. First, in part because our approach has been theoretical, it will be important to subject the predictions of our theoretical model to empirical testing. For example, though a few prior studies appear generally consistent with Propositions 1 and 2, research in low tech industries is limited as is the systematic study of factors such as the awareness of and ability to learn from indirect partners. Moreover, while the consistency of our brief comparative case of AMD versus NSC with Proposition 4 is promising (Sect. 6.1), empirical refutation through a largescale empirical design would be necessary. Such empirical tests might answer a number of related questions: Do measures of firms' learning horizon predict alliance formation and firm learning? Can they predict the inter-temporal stability of firms' alliance portfolio size? If so, then how will such effects vary across industries with different levels of technological uncertainty? Reliance on secondary data may not suffice to address such questions because learning horizons can vary in their extent with the awareness of and ability to learn from indirect partners. Thus, surveys may be used to gauge firms' view of the partner landscape (e.g., Lhuillery and Pfister 2011).

Second, our model is based on the assumption that within a technological paradigm, it is eventually possible to discern one optimal technological trajectory. This assumption is reasonable in light of multiple and diverse corroborative industry cases (e.g., Anderson and Tushman 1990; Cusumano et al. 1992; Suarez and Utterback 1995). Nonetheless, it is of course possible that, at least in the 
intermediate term, multiple trajectories cannot easily be distinguished based on projections regarding their feasibility, marketability, and profitability. Future research might account for the possibility of multiple concurrent optimal trajectories in the intermediate term, which mathematically amounts to defining $T$ to be a vector of values (e.g., Raiffa and Schlaifer 1961; Zellner 1971). We speculate that our results will remain similar in spirit under the assumption that the elements of the vector of optima are somehow positively correlated, such that observations obtained through alliances at once allow firms to update their beliefs about all conceivable optima. In practice, this is plausible either if the technologies underlying multiple optimal trajectories are comparable on at least a subset of all relevant technological dimensions or if they are complementary in defining a common application domain (e.g., Kodama 1991).

In conclusion, our study extends the alliance literature by offering a formal and integrative account of the role of indirect partners in optimal alliance portfolio design, generating several normative propositions amenable to future empirical refutation. We hope our theory offers an impetus for further exploration of the effects of firms' learning horizon on the formation and consequences of alliances by firms faced with technological uncertainty.

Acknowledgments We thank Joel Baum, Rene Belderbos, Robin Cowan, Santi Furnari, and seminar participants at Maastricht University for helpful comments and discussion. During part of the research for this article, Hans Frankort was a Visiting Scholar at the University of Toronto's Joseph L. Rotman School of Management.

Open Access This article is distributed under the terms of the Creative Commons Attribution 4.0 International License (http://creativecommons.org/licenses/by/4.0/), which permits unrestricted use, distribution, and reproduction in any medium, provided you give appropriate credit to the original author(s) and the source, provide a link to the Creative Commons license, and indicate if changes were made.

\section{Appendix: Derivation of the posterior variance (Eq. (3))}

Suppose the covariance matrix for the observations $x_{1}, x_{2}, \ldots, x_{\eta}$ is given by $\sum_{x}^{\eta}$. Each variable $x_{i}$ is normally distributed with mean $T$ and variance $\sigma_{x_{i}}^{2}$. The posterior distribution function is $f\left(x_{1}, \ldots, x_{\eta}, T\right)=f\left(x_{1}, \ldots, x_{\eta} \mid T\right) \cdot f(T) \propto$ $\exp \left(-\frac{1}{2}(x-\imath T)^{T}\left(\sum_{x}^{\eta}\right)^{-1}(x-\imath T)\right) \cdot \exp \left(-\frac{1}{2} \frac{(T-\mu)^{2}}{\sigma_{T}^{2}}\right)$, where $\imath$ is an $\eta$ by 1 vector whose elements contain the number 1 and $x$ is an $\eta$ by 1 vector containing the observations $x_{i}$. To determine the posterior variance of $T$ it suffices to collect all terms that involve $T^{2}$, i.e., $\left(l^{T}\left(\sum_{x}^{\eta}\right)^{-1} l+\frac{1}{\sigma_{T}^{2}}\right) T^{2}$. Because we assume that observations are independently and identically distributed, $\left(l^{T}\left(\sum_{x}^{\eta}\right)^{-1} l+\frac{1}{\sigma_{T}^{2}}\right) T^{2}=$ $\left(\sum_{i=1}^{\eta} \frac{1}{\sigma_{x}^{2}}+\frac{1}{\sigma_{T}^{2}}\right) T^{2}$. Therefore, the posterior variance of $T$ is equal to $\sigma_{\eta}^{2}=\left(\frac{\eta}{\sigma_{x}^{2}}+\frac{1}{\sigma_{T}^{2}}\right)^{-1}$. 


\section{References}

Adner R, Polos L, Ryall M, Sorenson O (2009) The case for formal theory. Acad Manag Rev 34(2):201-208

Ahuja G (2000) Collaboration networks, structural holes, and innovation: a longitudinal study. Adm Sci Q 45(3):425-455

Anderson P, Tushman ML (1990) Technological discontinuities and dominant designs: a cyclical model of technological change. Adm Sci Q 35(4):604-633

Arora A, Gambardella A (1990) Complementarity and external linkages: the strategies of the large firms in biotechnology. J Ind Econ 38(4):361-379

Arthur WB (1989) Competing technologies, increasing returns, and lock-in by historical events. Econ J 99(394):116-131

Auster ER (1992) The relationship of industry evolution to patterns of technological linkages, joint ventures, and direct investment between U.S. and Japan. Manag Sci 38(6):778-792

Boyd DE, Spekman RE (2008) The market value impact of indirect ties within technology alliances. J Acad Mark Sci 36(4):488-500

Breschi S, Malerba F, Orsenigo L (2000) Technological regimes and Schumpeterian patterns of innovation. Econ J 110(463):388-410

Bresnahan TF, Greenstein S (1999) Technological competition and the structure of the computer industry. $\mathrm{J}$ Ind Econ 47(1): 1-40

Burt RS (2010) Neighbor networks: competitive advantage local and personal. Oxford University Press, Oxford

Cassiman B, Veugelers R (2006) In search of complementarity in innovation strategy: internal R\&D and external knowledge acquisition. Manag Sci 52(1):68-82

Chandler AD Jr (2005) Inventing the electronic century: the epic story of the consumer electronics and computer industries. Harvard University Press, Cambridge

Cuneo P, Mairesse J (1984) Productivity and R\&D at the firm level in French manufacturing. In: Griliches Z (ed) R\&D, patents, and productivity. The Chicago University Press, Chicago, pp 375-392

Cusumano M, Mylonadis Y, Rosenbloom R (1992) Strategic maneuvering and mass-market dynamics: the thriumph of VHS over Beta. Bus Hist Rev 66(1):51-95

Cyert RM, DeGroot MH (1987) Bayesian analysis and uncertainty in economic theory. Rowman \& Littlefield, New Jersey

Deeds DL, Hill CWL (1996) Strategic alliances and the rate of new product development: an empirical study of entrepreneurial biotechnology firms. J Bus Ventur 11(1):41-55

DeGroot MH (1970) Optimal statistical decisions. McGraw-Hill, New York

Dosi G (1982) Technological paradigms and technological trajectories: a suggested interpretation of the determinants and directions of technical change. Res Policy 11(3):147-162

Dosi G (1988) Sources, procedures, and microeconomic effects of innovation. J Econ Lit 25(3):1120-1171

Dyer J, Furr N, Lefrandt C (2014). The industries plagued by the most uncertainty, Harvard Business Review, digital article, 11 Sep 2014

Eisenhardt KM, Schoonhoven CB (1996) Resource-based view of strategic alliance formation: strategic and social effects in entrepreneurial firms. Organ Sci 7(2):136-150

Faems D, Janssens M, Neyens I (2012) Alliance portfolios and innovation performance: connecting structural and managerial perspectives. Group Org Manag 37(2):241-268

Frankort HTW (2013) Open innovation norms and knowledge transfer in interfirm technology alliances: evidence from information technology, 1980-1999. Adv Strateg Manag 30:239-282

Frankort HTW, Hagedoorn J, Letterie W (2012) R\&D partnership portfolios and the inflow of technological knowledge. Ind Corp Change 21(2):507-537

Garud R, Nayyar PR, Shapira Z (1997) Technological choices and the inevitability of errors. In: Garud R, Nayyar PR, Shapira ZB (eds) Technological innovation: oversights and foresights. Cambridge University Press, Cambridge, pp 20-40

Ghosh A, Rosenkopf L (2014) Shrouded in structure: challenges and opportunities for a friction-based view of network research. Organ Sci 26(2):622-631

Gomes-Casseres B, Hagedoorn J, Jaffe AB (2006) Do alliances promote knowledge flows? J Financ Econ 80(1):5-33 
Grove AS (1996) Only the paranoid survive: how to exploit the crisis points that challenge every company. HarperCollins Business, New York

Gulati R, Gargiulo M (1999) Where do interorganizational networks come from? Am J Sociol 104(5):1439-1493

Hagedoorn J (2002) Inter-firm R\&D partnerships: an overview of major trends and patterns since 1960. Res Policy 31(4):477-492

Hagedoorn J (2006) Understanding the cross-level embeddedness of interfirm partnership formation. Acad Manag Rev 31(3):670-680

Hagedoorn J, Letterie W, Palm F (2011) The information value of R\&D alliances: the preference for local or distant ties. Strateg Organ 9(4):283-309

Hall BH, Jaffe A, Trajtenberg M (2005) Market value and patent citations. Rand J Econ 36(1):16-38

Harrigan K (1985) Joint ventures, alliances, and corporate strategy. Lexington Books, Lexington

Iyer B, Lee C-H, Venkatraman N (2006) Managing in a "small world ecosystem": lessons from the software sector. Calif Manag Rev 48(3):28-47

Kapoor R (2013) Persistence of integration in the face of specialization: how firms navigated the winds of disintegration and shaped the architecture of the semiconductor industry. Organ Sci 24(4):1195-1213

Kapoor R, McGrath PJ (2014) Unmasking the interplay between technology evolution and R\&D collaboration: evidence from the global semiconductor manufacturing industry, 1990-2010. Res Policy 43(3):555-569

Kim T-Y, Oh H, Swaminathan A (2006) Framing interorganizational network change: a network inertia perspective. Acad Manag Rev 31(3):704-720

Kodama F (1991) Analyzing Japanese high technologies: the techno-paradigm shift. Pinter Publishers, London

Kogut B, Zander U (1992) Knowledge of the firm, combinative capabilities, and the replication of technology. Organ Sci 3(3):383-397

Koka BR, Prescott JE (2008) Designing alliance networks: the influence of network position, environmental change, and strategy on firm performance. Strateg Manag J 29(6):639-661

Lahiri N, Narayanan S (2013) Vertical integration, innovation, and alliance portfolio size: implications for firm performance. Strateg Manag J 34(9):1042-1064

Lavie D (2006) The competitive advantage of interconnected firms: and extension of the resource-based view. Acad Manag Rev 31(3):638-658

Letterie W, Hagedoorn J, van Kranenburg H, Palm F (2007) Information gathering through alliances. J Econ Behav Organ 66(2):176-194

Lhuillery S, Pfister E (2011) Do firms know the scope of their R\&D alliance network? An empirical investigation of the determinants of network awareness on French survey data. Ind Innov 18(1):105-130

Liebowitz SJ, Margolis SE (1995) Path dependence, lock-in, and history. J Law Econ Organ 11(1):205-226

Mody A (1993) Learning through alliances. J Econ Behav Organ 20(2):151-170

Mowery DC, Oxley JE, Silverman BS (1996) Strategic alliances and interfirm knowledge transfer. Strateg Manag J 17(Winter Special Issue):77-91

Mowery DC, Oxley JE, Silverman BS (1998) Technological overlap and interfirm cooperation: implications for the resource-based view of the firm. Res Policy 27(5):507-523

Nelson RR, Winter SG (1982) An evolutionary theory of economic change. Harvard University Press, Cambridge

Oxley J, Wada T (2009) Alliance structure and the scope of knowledge transfer: evidence from U.S.Japan agreements. Manag Sci 55(4):635-649

Porac JF, Thomas H, Wilson F, Paton D, Kanfer A (1995) Rivalry and the industry model of Scottish knitwear producers. Adm Sci Q 40(2):203-227

Powell WW, Koput KW, Smith-Doerr L (1996) Interorganizational collaboration and the locus of innovation: networks of learning in biotechnology. Adm Sci Q 41(1):116-145

Powell WW, White DR, Koput KW, Owen-Smith J (2005) Network dynamics and field evolution: the growth of interorganizational collaboration in the life sciences. Am J Sociol 110(4):1132-1205

Raiffa H, Schlaifer R (1961) Applied statistical decision theory. MIT Press, Cambridge

Roijakkers N, Hagedoorn J (2006) Inter-firm R\&D partnering in pharmaceutical biotechnology since 1975: trends, patterns, and networks. Res Policy 35(3):431-446

Rosenkopf L, Padula G (2008) Investigating the microstructure of network evolution: alliance formation in the mobile communications industry. Organ Sci 19(5):669-687 
Rosenkopf L, Schilling MA (2007) Comparing alliance network structure across industries: observations and explanations. Strateg Entrep J 1(3-4):191-209

Rothaermel FT, Boeker W (2008) Old technology meets new technology: complementarities, similarities, and alliance formation. Strateg Manag J 29(1):47-77

Rothaermel FT, Deeds DL (2006) Alliance type, alliance experience and alliance management capability in high-technology ventures. J Bus Ventur 21(4):429-460

Sahal D (1981) Patterns of technological innovation. Addison-Wesley, Reading

Salman N, Saives AL (2005) Indirect networks: an intangible resource for biotechnology innovation. R\&D Manag 35(2):203-215

Schilling MA (2015) Technology shocks, technological collaboration, and innovation outcomes. Organ Sci 26(3):668-686

Schilling MA, Phelps CC (2007) Interfirm collaboration networks: the impact of large-scale network structure on firm innovation. Manag Sci 53(7):1113-1126

Soh P-H, Roberts EB (2005) Technology alliances and networks: an external link to research capability. IEEE Trans Eng Manag 52(4):419-428

Steensma HK, Marino L, Weaver KM, Dickson PH (2000) The influence of national culture on the formation of technology alliances by entrepreneurial firms. Acad Manag J 43(5):951-973

Suarez FF, Utterback JM (1995) Dominant designs and the survival of firms. Strateg Manag J 16(6):415-430

Sutcliffe KM, Huber GP (1998) Firm and industry as determinants of executive perceptions of the environment. Strateg Manag J 19(8):793-807

Sytch M, Tatarynowicz A, Gulati R (2011) Toward a theory of extended contact: the incentives and opportunities for bridging across network communities. Organ Sci 23(6):1658-1681

United States Census Bureau (2012) Number of firms, number of establishments, employment, annual payroll, and estimated receipts by enterprise employment size for the United States, all industries: 2012, www2.census.gov/econ/susb/data/2012/us_6digitnaics_2012.xls

Van de Ven AH (1976) On the nature, formation, and maintenance of relations among organizations. Acad Manag Rev 1(4):24-36

Vanhaverbeke W, Gilsing V, Duysters G (2012) Competence and governance in strategic collaboration: the differential effect of network structure on the creation of core and noncore technologies. J Prod Innov Manag 29(5):784-802

Vanhaverbeke W, Belderbos R, Duysters G, Beerkens B (2014) Technological performance and alliances over the industry life cycle: evidence from the ASIC industry. J Prod Innov Manag 32(4):556-573

Walker G, Kogut B, Shan W (1997) Social capital, structural holes and the formation of an industry network. Organ Sci 8(2):109-125

Westphal M (2008) The resource characteristics of strategic alliances. Acad Manag Rev 33(2):553-557

Zajac EJ, Bazerman MH (1991) Blind spots in industry and competitor analysis: implications of interfirm (mis)perceptions for strategic decisions. Acad Manag Rev 16(1):3

Zellner A (1971) An introduction to Bayesian inference in econometrics. Wiley, Chichester

Hans T. W. Frankort is Associate Professor (Senior Lecturer) in Strategy at Cass Business School, City University London. His main research focuses on the determinants and consequences of interorganizational relationships, with particular emphasis on research and development alliances in technologyintensive industries. His work has appeared in Academy of Management Journal, Advances in Strategic Management, Industrial and Corporate Change, and Research Policy, among others.

John Hagedoorn is Professor of Strategy and International Business at the School of Management, Royal Holloway University of London. He is also a Professorial Fellow at the Maastricht Economic Research Institute on Innovation and Technology (UNU-MERIT) and Professor Emeritus at the School of Business and Economics, Maastricht University. His research focuses on interfirm partnerships and contract law, mergers and acquisitions, innovation and technological change, and international strategy. His work has appeared in Academy of Management Journal, Academy of Management Review, Advances in Strategic Management, Business History, Business History Review, Global Strategy Journal, Industrial and Corporate Change, International Journal of Industrial Organization, Journal of Common Market Studies, Journal of Economic Behavior and Organization, Journal of Empirical Legal Studies, Journal of Financial 
Economics, Journal of International Business Studies, Journal of Management Studies, Managerial and Decision Economics, Organization Studies, Research Policy, Review of Industrial Organization, Small Business Economics, Strategic Management Journal, Strategic Organization, and Technovation, among others.

Wilko Letterie is Associate Professor at the School of Business and Economics, Maastricht University. His research focuses on factor demand decisions and alliance formation under uncertainty. His work has appeared in Economica, Economics Letters, Industrial and Corporate Change, Journal of Economic Behavior and Organization, Journal of Law, Economics, and Organization, Journal of Monetary Economics, Oxford Bulletin of Economics and Statistics, Public Choice, Research Policy, The Review of Economics and Statistics, Scandinavian Journal of Economics, Small Business Economics, Social Choice and Welfare, and Strategic Organization, among others. 